\title{
Team Sport Players' Perception of Imagery Use and Confidence in Sport 參與隊際運動對意象及信心的關係
}

\author{
ADEGBESAN, Olufemi Adegbola \\ Department of Physical Education, Health \& Recreation, \\ University of Botswana, Gaborone, BOTSWANA
}

艾狄比臣

非洲博茨瓦納大學體育健康及康樂學系

\begin{abstract}
The relationship of imagery use and confidence were examined on forty-eight elite male team sport players in volleyball, basketball and football from Botswana with mean age $\{\mathrm{M}=22.50 ; 1.32\}$ using Sport Imagery Questionnaire \{SIQ\} and the Sources of Sport Confidence Questionnaire $\{$ SSCQ\} The result of the correlation matrix indicated a positive but moderate relationship of perceived imagery use and sport confidence with correlation value ranging from $\mathrm{r}=.30$ to .77 . The result further revealed an apparent significant $\{\mathrm{P}<.05\}$ composite effect of the imagery use on the team sport players' sport confidence. The reflection of the dual motivational and cognitive functions of imagery use for the prediction of the team sport players' sport confidence was also revealed in the study.
\end{abstract}

\section{摘 要}

本文旨在探討博茨瓦納青年人參與排球、籃球和足球等隊際運動對意象及信心的關係，結果顯示兩者存有明顯的正相關。

\section{Introduction}

Imagery has been demonstrated to be an effective means of enhancing performance in sport (Hall, 2001; Fish et al, 2004; Munroe-Chandler \& Strachan, 2006; Smith et al, 2007). It is any experience that mimics sensory or perceptual experiences, in which the athletes are consciously aware of their imagery experience. Paivio (1985) identified the dual functional roles through which imagery influences sport performance, and the frame work he developed has been the guide for studies found in the imagery literature. The framework indicates that imagery mediates behaviour and affects sport performance through the cognitive and motivational functions. The cognitive function includes techniques and specific skill practice and the motivational functions consist of emotional control, overcoming adversity and being successful. These two imagery functions operate at either specific or general level.

Imagery use by athletes in recent years has been broadly categorized into five functions based on the Sport Imagery Questionnaire developed by Hall et al (1998), these functions are cognitive specific (CS), which involves imagery that focuses on improving a specific motor skill, cognitive general (CG), dimension involves imaging any combination of movement such as game plan and routine. The others are motivational specific (MS), which is used to imaging achieving successful personal goals, motivation general mastery (MGM), which requires the individual to imagine being tough mentally and confident in all situations, and motivation general arousal (MGA), which focused on different feelings such as stress, arousal, anxiety associated with sport and relaxation. 
Confidence has been one of the most consistent factors which distinguished successful athletes from nonsuccessful athletes (Gould et al,1981).Sport confidence according to Vealey (1986) refers to the belief or degree of certainty an athlete possesses about his or her ability to be successful in sport. The reconceptualisation of the model of sport confidence by Vealey et al (1998) consequently identified the sources of sport confidence that were specifically salient to athletes. These sources consist of variables such as mastery, demonstration of ability, physical/mental preparation, physical self-presentation, social support, vicarious experience, coaches' leadership, environmental comfort and situational favorableness. The sport confidence model was also conceptualized into trait (sc-trait) and state (sc-state) components, and also includes a dispositional construct termed competitive orientation, which refers to an athlete's tendency to strive towards achieving a certain type of goal when competing in sport (Vealey et al, 1998). The emphasis on confidence in sport research was justified by Moritz et al (2000) because of its strong relationship to sport performance and success. It has been shown to be a consistent psychological construct which aids performance enhancement in sport, and given the relationship that exist between confidence and sport performance, there is need to have specific psychological techniques to develop, maintain and regain confidence among athletes, and imagery is one of these techniques (Vealey, 2001; Bandura, 1997).

Theoretically, a connection between imagery and confidence was proposed in earlier studies such as Feltz (1984) and Martin and Hall (1995) which were specifically based on Bandura's self efficacy theory, in which it was proposed that a successful image may provide an individual with vicarious information which could serve to enhance self efficacy and therefore sport confidence. The applied model of imagery use in sport by Martin et al (1999) outlined a guiding framework of athletes' use of imagery in order to achieve a range of performance and skill outcomes in their sport. These outcomes consist of the acquisition and improved performance of skills and strategies, modification of cognitions and regulation of arousal and anxiety, which are all moderated by imagery ability. The model predicts that different types of imagery are associated with different expected outcomes. Learning and rehearsal of skills and strategies are predicted to be associated with cognitive specific and cognitive general imagery, while regulation of arousal and competitive anxiety are predicted by the us of motivation general arousal imagery. Modification of cognition such as selfefficacy and self confidence, are predicted to be primarily associated with the motivation general mastery type of imagery.

Many empirical research have reported a relationship between imagery, and sport confidence (e.g.Abma et al, 2002; Mills et al, 2002; Callow and Hardy, 2001; Vadocz et al, 1997). Specifically, Callow and Hardy found that cognitive (CG) and motivation general mastery (MGM) were related to state confidence in lower skilled county netballers, whereas motivational specific(MS) was related to state confidence in higher skilled county netball players. The findings in Abma et al (2002) showed that highly confident athletes compared to their less confident counterparts used all five functions of imagery more frequently. While Mills et al (2000) reported that high confident sport group used more motivational specific (MS), motivation general mastery (MGM), and motivation general arousal (MGA) compared to low confident sport group. The study by Callow, Hardy and Hall (2001) examined the effects of motivation general mastery (MGM) on the confidence of elite badminton players and the results showed that a 20 week imagery intervention programme improved the sport confidence for two of the three players and stabilized the sport confidence of the third player.

The author identified two studies such as Callow and Hardy (2001), and Short and Short (2005) that examined imagery and sport confidence relationship in team sport (e.g. netball and football), and theoretically it is understandable that imagery type such as cognitive general (CG) may be linked to confidence with team sport athletes. The self efficacy beliefs as postulated by Bandura (1997) are constructed from four principles sources of information which are enactive mastery, vicarious experience, verbal persuasion, physiological and affective status. With regards to vicarious experience, Callow and Hardy (2001) were of the opinion that the application of imagery type such as cognitive general (CG) to a team sport could provides an avenue that allows an athlete to image his or her team mates successfully executing strategies, consequently the athlete imaging would gain vicarious experience about the sport specific task and therefore self confidence about the his or her ability to perform. 
The purpose of this study was therefore to examine whether significant relationship exist between the team sport imagery use and the sport confidence, it is also hypothesized that each type of imagery use by the athletes would predict the sport confidence of these team sport athletes from a developing country. The premise for the formulated hypothesis was based on the theoretical link of imagery type such as motivation general mastery (MGM), and motivational specific (MS) with sport confidence (Vealey, 1986; Feltz, 1984).

\section{Methods}

\section{Participants}

The initial samples used in this study were 48 male elite players in volleyball, basketball and football from Botswana. 3 players from football did not complete the sources of sport confidence questionnaire and therefore finally excluded from the study. The final sample used was 45 with 15 participants each for each sport. Their mean age ranged from 19 to 26 years $(M=22.50$; $\mathrm{SD}=1.32$ ). All the participants have had some level training in mental skill technique and have had at least one year playing experience at the elite level.

\section{Measures}

The 30-items Sport Imagery Questionnaire developed by Hall et al (1998) to measure imagery functions in sport was used for the study. These imagery functions consist of five subscales of Cognitive General (CG), Cognitive Specific (CS), Motivational Specific (MS), Motivation General Mastery (MGM), Motivation General arousal (MGA). Each imagery function consist of 6 items and the items are rated on a 7-point Likert Scale (1=rarely and $7=0$ ften). The scores for the subscales are calculated as the sum of the item scores for that subscale. Previous research have shown acceptable internal consistency for the (SIQ) subscales which ranged from .68 to .90(Hall et al, 1998; Abma et al , 2002). In this present study, the cronbach alpha coefficient for the (SIQ) subscales ranged from .68 to .89 .

The Sources of Sport Confidence Questionnaire developed by Vealey et al (1998) was the second instrument used in this study. The instrument is a 7-point Likert Scale that ranged from (1=not at all important) to ( $7=$ of highest importance). It consist of 9 subscales of Mastery, Demonstration of Ability, Physical/Mental Preparation, Physical Self Presentation, Social Support,
Coaches Leadership, Vicarious Experience, Environmental Comfort and Situational Favorableness. The instrument comprises of 43 items, however 41 items were used for this study based on Vealey's et al (1998) submission that the item 'Win' under the subscale of demonstration of ability and item 'follow certain rituals' under the subscale of environmental comfort were deleted from the inventory due to the significantly lower loadings and squared multiple correlations than other items. The overall alpha coefficient was .90 which is a representation of acceptable generalized measure of reliability for the entire model. The internal consistency measure for the (SSCQ) subscales for this study ranged from .71 to .87 . The validity of the (SSCQ) is reflected in Vealey et al (1998) in which several predictions including the subscales on SC-trait, in an attempt to examine the link between sources and levels of sport confidence were made.

\section{Procedures}

Approval to use the participants was sought from the team officials and the informed consent to participate in the study. The study was explained by the and the research assistants to the participants who volunteered for the research. The Sport Imagery Questionnaire was administered to the participants and after an interval of a week the Sources of Sport Confidence Questionnaire was also administered to he same participants prior to their matches at the different venues. Similar procedure was used by Callow and Hardy (2001), and each participant completed the filling of the questionnaire independently.

\section{Data Analysis}

The SPSS statistical package was used for the analysis of data. The internal consistency for the (SIQ) and the (SSCQ) was done using the cronbach alpha coefficient. The descriptive statistics of mean and standard deviation were also utilized. The pearson correlation was use to determine the relationships, and multiple regression analysis was also used for the prediction.

\section{Results}

This study examined the relationships of the sport imagery types on sports confidence of team sport players and also examined whether imagery thus predicts the players sport confidence. Sufficient internal consistencies were established for the subscales of sport imagery and sport confidence. 
Table 1. Correlation Matrix, Means, Standard Deviation and Cronbach Coefficient Alpha by Sport Imagery Types and Confidence Sub-Scales $(n=45)$.

\begin{tabular}{|c|c|c|c|c|c|c|c|c|c|c|c|c|c|c|c|c|}
\hline & M & SD & 1 & 2 & 3 & 4 & 5 & 6 & 7 & 8 & 9 & 10 & 11 & 12 & 13 & 14 \\
\hline Cognitive Specific & 30.9 & 7.53 & $.81^{+}$ & $.49^{*}$ & $.60^{*}$ & $.30 *$ & $.47 *$ & $.34^{*}$ & $.70^{*}$ & $.54 *$ & $.64 *$ & $.77 *$ & $.52 *$ & $.61^{*}$ & $.54 *$ & $.42 *$ \\
\hline Cognitive General & 28.4 & 9.92 & & $.74^{+}$ & $.41^{*}$ & $.31 *$ & $.64 *$ & $.46^{*}$ & $.58^{*}$ & $.62 *$ & $.51 *$ & $.60 *$ & $.57 *$ & $.42 *$ & $.58 *$ & $.33 *$ \\
\hline $\begin{array}{l}\text { Motivational } \\
\text { Specific }\end{array}$ & 35.7 & 6.99 & & & $.89^{+}$ & $.37^{*}$ & $.42 *$ & $.66^{*}$ & $.71 *$ & $.40^{*}$ & $.59 *$ & $.52 *$ & $.54^{*}$ & $.63^{*}$ & $.47 *$ & $.51^{*}$ \\
\hline $\begin{array}{l}\text { Motivational General } \\
\text { Mastery }\end{array}$ & 28.5 & 10.2 & & & & $.76^{+}$ & $.56^{*}$ & $.46^{*}$ & $.43^{*}$ & $.59 *$ & $.61^{*}$ & $.64^{*}$ & $.51^{*}$ & $.40^{*}$ & $.53 *$ & $.49 *$ \\
\hline $\begin{array}{l}\text { Motivational General } \\
\text { Arousal }\end{array}$ & 34.8 & 7.56 & & & & & $.68^{+}$ & $.41^{*}$ & $.52 *$ & $.46^{*}$ & $.68 *$ & $.59 *$ & $.67^{*}$ & $.62 *$ & $.44^{*}$ & $.51^{*}$ \\
\hline Mastery & 31.3 & 6.46 & & & & & & $.74^{+}$ & $.55^{*}$ & $.59 *$ & $.47 *$ & $.50^{+}$ & $.52^{+}$ & $.64^{+}$ & $.62^{+}$ & $.40 *$ \\
\hline Demo of Ability & 27.8 & 4.89 & & & & & & & $.71^{+}$ & $.44^{*}$ & $.55^{*}$ & $.30^{*}$ & $.46^{*}$ & $.39 *$ & $.48^{*}$ & $.55^{*}$ \\
\hline $\begin{array}{l}\text { Physical/Mental } \\
\text { Preparation }\end{array}$ & 22.1 & 4.53 & & & & & & & & $.77^{+}$ & $.41 *$ & $.59 *$ & $.64 *$ & $.60 *$ & $.42 *$ & $.40^{*}$ \\
\hline $\begin{array}{l}\text { Physical Self } \\
\text { Presentation }\end{array}$ & 30.6 & 6.74 & & & & & & & & & $.73^{+}$ & $.39 *$ & $.48^{*}$ & $.55^{*}$ & $.50 *$ & $.49 *$ \\
\hline Social Support & 34.6 & 7.40 & & & & & & & & & & $.87^{+}$ & $.61 *$ & $.59 *$ & $.46^{*}$ & $.44^{*}$ \\
\hline Coaches Leadership & 18.7 & 7.30 & & & & & & & & & & & $.79^{+}$ & $.48 *$ & $.50^{*}$ & $.49^{*}$ \\
\hline Varicious Experience & 28.9 & 6.48 & & & & & & & & & & & & $.82^{+}$ & $.46^{*}$ & $.51 *$ \\
\hline $\begin{array}{l}\text { Environmental } \\
\text { Comfort }\end{array}$ & 16.7 & 4.57 & & & & & & & & & & & & & $.76^{+}$ & $.49 *$ \\
\hline $\begin{array}{l}\text { Situational } \\
\text { Favourableness }\end{array}$ & 25.1 & 4.68 & & & & & & & & & & & & & & $.84^{+}$ \\
\hline
\end{tabular}

${ }^{*} \mathrm{P}<.01=$ Significant

${ }^{+}$Cronbach Coefficient alpha on diagonal

The Cronbach alpha coefficients for the imagery subscales were: Cognitive Specific $\alpha=.81$; Cognitive General $\alpha=.74$; Motivation Specific $\alpha=.89$; Motivational general mastery $\alpha=.76$; and Motivational general arousal $\alpha=.68$. While the cronbach alpha coefficient for the sport confidence subscales ranged from $\alpha=.71$ to $\alpha=$ .87. The demonstration of ability recorded the lowest coefficient alpha, while the social support subscale had the highest coefficient alpha as shown diagonally in Table 1. The descriptive statistics of mean and standard deviation were also shown in the table. The mean scores ranged from moderate to strong for the perceived imagery functions used, as well as the team sport sources of sport confidence for the imagery subscales and the sport confidence. Pearson correlations were computed and positive relationships though moderate were also recorded for the team sports perceived sport imagery use and sport confidence and the correlation values ranged from $r=.30$ to $\mathrm{r}=.77$. 
Table 2. Composite Effect of the Sport Imagery Use on Sport Confidence Showing the ANOVA Summary of the Regression Analysis.

\begin{tabular}{llllll}
\hline Model & Sum of Square & Mean & Df & F & Sig \\
\hline Regression & 770.909 & 85.557 & 9 & & \\
Residual & 4489.091 & 128.260 & 35 & 2.66 & .032 \\
Total & 5260.000 & & 44 & & \\
\hline
\end{tabular}

$\mathrm{R}=.383$

$\mathrm{R}^{2}=.147$

Adj $R^{2}=0.73$

Standard Error $=11.325$

Hierarchical regression was also conducted with each of the sport imagery subscales which is the dependent measures and the sport confidence subscales as the independent measure or the predictor variables. It was apparent that the perceived imagery use had significant composite effect $\mathrm{F}(9.35)=2.66: \mathrm{p}<.05$ on the team sports players confidence as shown in Table 2. The perceived sport imagery use was also found to have contributed $\left\{14.7 \% ; \mathrm{R}^{2}=.147\right\}$ to the variance of the team sport players sport confidence.

Table 3. Parameter Estimate of the Relative Contribution of Sport Imagery Types on Sport Confidence.

\begin{tabular}{|c|c|c|c|c|c|}
\hline Variables & Unstandardised & coefficient & Standardized Coefficient & $\mathrm{t}$ & Sig \\
\hline & $\beta$ & $\begin{array}{l}\text { Standard } \\
\text { Error }\end{array}$ & Beta & & \\
\hline (Constant) & 65.37 & 13.105 & & 4.98 & $.000 *$ \\
\hline Mastery & .140 & .296 & .083 & 2.78 & $.012 *$ \\
\hline Demonstration of Ability & .111 & .465 & .050 & 2.62 & $.022 *$ \\
\hline Physical/Mental Preparation & 6.685 & .410 & .040 & .163 & $.642 * *$ \\
\hline Physical Self-Presentation & .172 & .475 & .074 & 3.61 & $.000 *$ \\
\hline Social Support & .106 & .451 & .072 & 2.10 & $.036^{*}$ \\
\hline Coaches Leadership & .443 & .427 & .020 & 1.69 & $.521^{* *}$ \\
\hline Vicarious Experience & .307 & .314 & .182 & 2.44 & $.000 *$ \\
\hline Environmental Comfort & .640 & .646 & .268 & 1.69 & $.061 * *$ \\
\hline Situational Favorableness & .854 & .564 & .366 & 2.74 & $.018^{*}$ \\
\hline
\end{tabular}

\footnotetext{
*: Significant at $\mathrm{P}<.05$

**: Not significant at $\mathrm{P}>.05$
} 
The results in Table 3 revealed that the sport imagery use significantly $(\mathrm{p}<.05)$ predicted the sources of sport confidence of the team players on mastery, demonstration of ability, physical self-presentation, social support vicarious experience and situational favorableness sub-scales. While the significant prediction was not (p>.05) apparent with the sub-scales of physical/mental preparation, coaches leadership and environmental comfort. All the subscales for both the dependent and independent measures were above the commonly accepted internal constituency criterion of .70 (Nunnally, 1998), except for the motivational general arousal which was below the criterion value. This finding was similar to Hall et al (1998) and Abma et al, (2002) where the motivational general arousal subscale was below .70 .

\section{Discussion}

It is apparent from the results of this study that the imagery function is related to the confidence of the team sports players used in this study. The use of goal oriented imagery function such as the motivation specific (MS) as been found to be very effective for confidence enhancement in sport. A great motivational value according to Hardy (1998) for athletes through pressure period or in a long training period is the imaging of outcome goals which indeed enhances confidence that will propel the athletes to achieve their ultimate goals. The dual functions of imagery use in sport by team sport athletes could be complementary to boost their confidence during a game situation because some players may image strategies of play such as the cognitive specific and cognitive general (CS) and $\mathrm{CG}$ ) for the cognitive function of improving strategy while other team players may image strategies of play for the motivational functions such as the motivation specific (MS), motivational generalmastery (MG-M) and motivational general-arousal (MG-A) to psyche themselves up to use the strategies.

Significant prediction was found for sport confidence sources of mastery, demonstration of ability, physical self presentation, social support, various experience and situational favourableness. This prediction is the reflection of the dual motivational and cognitive functions of the imagery use because the sport confidence indicators also possess some elements of the dual functions of the imagery use.
Similar study such as Callow and Hardy (2001) with hierarchical regression analysis indicated that the sport imagery variables predicted a significant proportion of the variance in the sources of sport confidence inventory scores and it was apparently indicated as hypothesized that the premise for the prediction of confidence could be due to different types of imagery having a particular pertinence to the team sport players. Based on the theoretical tenets of social cognitive theory (Bandura, 1997) it is assumed that both personal and situational factors influence athletes confidence. The identification of the determinants of confidence judgement over a period of time especially with the complementary effect of imagery use leads to better prediction of team sports athletes' performance and the overall evaluation of the sport experience.

The findings of this study provide important theoretical and applied implication for further studies in imagery and confidence in team sports context. Specifically considering experimental designs that will demonstrate the effectiveness of different imagery functions as they moderate the relationship between imagery use and confidence express by team sport players in competitive situations.

\section{References}

Abma, C. L., Fry, M. D., Li, Y., \& Relyea, G. (2002) Differences in Imagery Content and Imagery ability between high and low confident track and field athletes. Journal of Applied Sport Psychology 14, 6775.

Bandura, A. (1997). Self-efficacy: The exercise control. New York: freeman.

Callow, N., \& Hardy, L. (2001). Types of Imagery Associated with Sport confidence in netball players of varying skill level. Journal of Applied Sport Psychology 13, 1-17.

Chandler-Munroe, K., \& Strachan, L. (2006). Using Imagery to Predict Self-confidence and anxiety in Young Elite Athletes. Journal of Imagery Research in Sport and Physical Activity. 1, 1-19. 
Feltz, D. L. (1984). Self-efficacy as a cognitive mediator of athlete performance. In W. F. Straub (Ed) Cognitive Sport Psychology (pp 191-198). Lansing, NY: Sport Science Associates.

Fish, L., Hall, C., \& Cumming, J. (2004). Investigating use of Imagery by Elite Ballet Dancers. Avante. 10. 26-39.

Gould, D. Weiss, M., \& Weinberg, R. (1981). Psychological Characteristics of Successful and NonSuccessful Big Ten Wrestlers. Journal of Sport Psychology, 3, 69-81.

Hall, C. R. (2001). Imagery in Sport and Exercise. In R. S. Singer, H. A. Hausenblas, C. M. Jornelle (Eds) Handbook of Sport Psychology (pp. 529-549). New York, Wiley.

Hall, C., Mack, D., Paivio, A., \& Hausenblas, H. (1998). Imagery use of athletes. Development of the imagery use questionnaire. International Journal of Sport Psychology, 34, 151-16

Hardy, L. (1998). Responses to the Reaction on three myths in applied consultancy work. Journal of Applied Sport Psychology, 9, 277-294.

Martin, K. A., \& Hall, C. (1995). Using mental imagery to enhance intrinsic motivation. Journal of Sport and Exercise Psychology, 12, 54-69.

Martin, K. A. Moritz, S. E., \& Hall, C. K. (1999). Imagery use in Sport: A Literature Review and Applied Model. The Sport Psychologist, 13, 245-268.

Mills, K. D., Munroe, K. J., \& Hall, C. R. (2000). The Relationship between Imagery and Self-Efficacy in Competitive Athletes. Imagination, Cognition, and Personality, 20, 33-39.

Moritz, S. E., Hall, C. Martin, K. A., \& Vadocz, E. (1996). What are confident Athletes Imagery? An Examination of Image Content. The Sport Psychologist, 10, 171179.
Nunnally, J. C. (1998). Psychometric Theory $\left(2^{\text {nd }}\right.$ ed) New York. McGraw-Hill.

Paivio, A. (1995). Cognitive and Motivational functions of imagery in human performance. Canadian Journal of Applied Sports Science 10, 22-28.

Short, S. E., \& Short, M. W. (2005). Differences between high and low Confident football players on Imagery Functions: A Consideration of the Athletes Perception. Journal of Applied Sport Psychology, 17, 197-208.

Smith, D., Wright, C. Allsopp, A., \& Westhead, H. (2007). Its all in the Mind.: Pettlep-based imagery and sport performance. Journal of Applied Sport Psychology, 19, 80-92.

Vadocz, E. A., Hall, C., \& Moritz, (1997). The relationship between competitive anxiety and imagery use. Journal of Applied Sport Psychology 9, 24 252 .

Vealey, R. S. (1986). Conceptualization of Sport-confidence and competitive orientation: Preliminary investigation and instrument development. Journal of Sports Psychology, 8, 221-246.

Vealey, R. S. (2001). Understanding and Enhancing SelfConfidence in athletes. In R. S. Singer, A. A. Hausenblaus \& C. M. Janelle (Eds). Handbook of Sport Psychology (pp 550-565). New York: Willey.

Vealey, R. S., Hayashi, S. W., Gerner-Holman, M., \& Giacobbi, P. (1998). Sources of Sport Confidence; Conceptualization and Instrument Development. Journal of Sport and Exercise Psychology, 20, 54-80.

\section{Correspondence:}

ADEGBESAN, Olufemi Adegbola PhD Department of Physical Education, Health \& Recreation, University of Botswana Gaborone, Botswana.

Email: adegbesano@mopipi.ub.bw or dokitafemi@yahoo.com 